\title{
Bacteriophages Infecting Gram-Negative Bacteria in a Commercial Cucumber Fermentation
}

\author{
Zhongjing Lu ${ }^{1 *}$, llenys M. Pérez-Díaz ${ }^{2,3}$, Janet S. Hayes ${ }^{2,3}$ and Fred Breidt ${ }^{2,3}$ \\ 'Department of Molecular \& Cellular Biology, Kennesaw State University, Kennesaw, GA, United States, ${ }^{2}$ United States \\ Department of Agriculture, Agricultural Research Service, Washington, DC, United States, ${ }^{3}$ Department of Food, \\ Bioprocessing \& Nutrition Sciences, North Carolina State University, Raleigh, NC, United States
}

\section{OPEN ACCESS}

Edited by:

Joaquin Bautista-Gallego, University of Extremadura, Spain

Reviewed by:

Gustavo Cordero-Bueso,

University of Cádiz, Spain

Victor Ladero,

Consejo Superior de Investigaciones

Cientificas (CSIC), Spain

*Correspondence:

Zhongjing Lu

jean_lu@kennesaw.edu

Specialty section:

This article was submitted to

Food Microbiology,

a section of the journal

Frontiers in Microbiology

Received: 28 January 2020

Accepted: 22 May 2020

Published: 26 June 2020

Citation:

Lu Z, Pérez-Díaz IM, Hayes JS and Breidt $F$ (2020) Bacteriophages Infecting Gram-Negative Bacteria in a Commercial Cucumber Fermentation.

Front. Microbiol. 11:1306.

doi: 10.3389/fmicb.2020.01306
Cucumber fermentations are one of the most important vegetable fermentations in the United States. The fermentation is usually driven by lactic acid bacteria ( $\angle A B)$ indigenous to fresh cucumbers. But $L A B$ are greatly outnumbered by many Gramnegative bacteria on fresh cucumbers, which may influence the growth of $L A B$ and the incidence of bloater defect (hollow cavities formed inside fermented cucumbers) leading to serious economic loss to the pickle industry. Rapid elimination of Gramnegative bacteria is crucial to the dominance of $L A B$ and the reduction of bloater defect in the fermentation. Various factors can affect the viability of Gram-negative bacteria in cucumber fermentation. Bacteriophages (phages) may be one of such factors. This study explored the abundance, diversity, and functional role of phages infecting Gramnegative bacteria in a commercial cucumber fermentation. Cover brine samples were taken from a commercial fermentation tank over a 30-day period. On day 1 and day 3 of the fermentation, 39 Gram-negative bacteria and 26 independent phages were isolated. Nearly $67 \%$ of Gram-negative bacterial isolates were susceptible to phage infection. Phage hosts include Enterobacter, Citrobacter, Escherichia, Pantoea, Serratia, Leclercia, Providencia, and Pseudomonas species. About $88 \%$ of the isolated phages infected the members in the family Enterobacteriaceae and $58 \%$ of phages infected Enterobacter species. Eight phages with unique host ranges were characterized. These phages belong to the Myoviridae, Siphoviridae, or Podoviridae family and showed distinct protein profiles and DNA fingerprints. The infectivity of a phage against Enterobacter cancerogenus was evaluated in cucumber juice as a model system. The phage infection at the multiplicity of infection 1 or 100 resulted in a 5-log reduction in cell concentration within $3 \mathrm{~h}$ and rapidly eliminated its host. This study revealed the abundance and variety of phages infecting Gram-negative bacteria, particularly Enterobacteriaceae, in the commercial cucumber fermentation, suggesting that phages may play an important role in the elimination of Gram-negative bacteria, thereby facilitating the dominance of $L A B$ and minimizing bloater defect. To our knowledge, this is the first report on the ecology of phages infecting Gram-negative bacteria in commercial cucumber fermentations.

Keywords: bacteriophage, Gram-negative bacteria, Enterobacteriaceae, Enterobacter, cucumber fermentation 


\section{INTRODUCTION}

Vegetable fermentation plays an important role in preserving foods and providing variety to the diet as well as enhancing the nutrient content of the food. Cucumber pickles are the most commonly consumed fermented vegetable in the United States and many other countries. Today, each American eats an average of 9 pounds of pickles a year (Kaplan, 2014). An average production of pickles in the United States is around 480,000 tons in 2012-2014 with an economic value between 145 and 175 million dollars (Anonymous, 2015). The global pickles market reached a value of US $\$ 10.3$ Billion in 2018, and the market is projected to cross US $\$ 12.3$ Billion by 2024 , according to the latest report by the International Market Analysis Research and Consulting Group (Anonymous, 2019).

Most cucumber fermentations are driven by lactic acid bacteria (LAB) naturally present on fresh cucumbers. The metabolic activities of LAB determine the quality and safety of the final products (Breidt et al., 2013a). Although LAB are naturally associated with fresh cucumbers, their initial concentration is usually below $0.4 \%$ of the bacterial population (Pérez-Díaz et al., 2019) and can be as low as $0.01-0.1 \%$ of the total microbiota (Mundt et al., 1967; Mundt and Hammer, 1968; Mundt, 1970). A wide variety of other bacteria greatly outnumber LAB. Gram-negative bacteria are typically predominant on fresh cucumbers (Pederson and Albury, 1950; Mundt et al., 1967; Mundt and Hammer, 1968; Mundt, 1970; Pérez-Díaz et al., 2019). Enterobacter and many other members in the Enterobacteriaceae family, Pseudomonas, and Providencia are frequently isolated during the early stage of cucumber fermentation (Veldhuis and Etchells, 1939; Etchells, 1941; Samish et al., 1957, 1963; PérezDíaz et al., 2019). The dominance of Gram-negative bacteria can interfere with the growth of $\mathrm{LAB}$ resulting in slow fermentation and affect thequality and/or safety of fermented cucumbers. In addition, many Gram-negative bacteria such as Enterobacter can contribute to the formation of hollow cavities or gas pockets in the interior of whole fruits, a defect known as bloater. Bloater defect downgrades the product quality and results in serious economic loss to the pickle industry (Fleming, 1979; Zhai et al., 2018). Although pathogenic bacteria have not been reported in commercially fermented vegetable products, the survival of certain acid-resistant bacterial pathogens can occur (Breidt and Caldwell, 2011). Some Gram-negative bacteria such as Salmonella and Escherichia coli O157:H7 can cause foodborne illness. The key to ensure successful cucumber fermentation as well as other vegetable fermentations is to establish conditions to promote the growth of LAB over other microorganisms, particularly Gram-negative bacteria so that LAB can quickly dominate in the fermentation system before Gram-negative bacteria and other undesirable microorganisms have a chance to increase substantially in numbers and exert their effects.

It has long been thought that only certain physical and chemical factors (e.g., added salt, oxygen depletion, acids produced, and resulting low $\mathrm{pH}$ ) affect the mortality of Gramnegative bacteria and other undesirable microbiota leading to the dominance of LAB in cucumber fermentations (Pederson and Albury, 1950; Pérez-Díaz et al., 2014). Biological factors such as phage infection are often overlooked. Phages are ubiquitous in nature and thus are a component of the microbiota in many habitats including fresh cucumbers and fermentation environments. Phages are natural killers of bacteria and can act as biological control agents. Therefore, phages can be an important factor regulating the abundance and distribution of bacterial populations, thereby influencing the microbial succession in cucumber fermentations. We previously investigated phages infecting LAB in commercial cucumber and sauerkraut fermentations (Lu et al., 2003b, 2012). We found abundant and diverse LAB phages present in those fermentations and explored their potential to influence the bacterial succession among LAB species. A recent study reported a phage isolated from cucumber fermentation infected a Gramnegative bacterium, Escherichia coli O157:H7 (Lu and Breidt, 2015). However, phages infecting other Gram-negative bacteria in cucumber fermentations have not been well studied. In this study, we explored the abundance, diversity, and ecological role of phages active against Gram-negative bacteria in a commercial cucumber fermentation, characterized eight phages isolated from the fermentation, and evaluated the infectivity of an isolated phage active against Enterobacter cancerogenus (a frequently occurring bacterium) in cucumber juice as a model system. The data from this study may provide new insight into our understanding of the dynamic process in cucumber fermentations and the development of bloater control strategy in cucumber fermentations. To our knowledge, this is the first report of the ecology of phages infecting Gram-negative bacteria in a commercial cucumber fermentation.

\section{MATERIALS AND METHODS}

\section{Industrial Cucumber Fermentation and Sample Collection}

A commercial cucumber fermentation tank (designated as Tank A, 40,000-L capacity) was examined in this study. The tank was packed with two sizes of cucumbers, size $3 \mathrm{~A}(44-51 \mathrm{~mm}$ in diameter) and size $2 \mathrm{~B}(32-38 \mathrm{~mm}$ in diameter). The recycled cover brine from previous cucumber fermentations was adjusted with $20 \%$ acetic acid and pickling salt in order to achieve $50 \mathrm{mM}$ acetic acid and $2 \mathrm{M} \mathrm{NaCl}$ in the cover brine for Tank A. After equilibration between whole cucumbers and the cover brine, the concentrations of acetic acid and sodium chloride $(\mathrm{NaCl})$ were $25 \mathrm{mM}$ and $1.03 \mathrm{M}(6 \%)$, respectively. The resulting $\mathrm{pH}$ was 4.4 at which the fermentation started. On each sampling day (days $1,3,7,14$, or 30 ), two cover brine samples were taken from two separate locations $(0.61$ and $2.44 \mathrm{~m}$ below the cover brine surface) in the fermentation tank. The samples were immediately transported to our laboratory on ice and processed on the same day.

\section{The Treatment of Cover Brine Samples for Host and Phage Isolations}

One ml of each cover brine sample was saved for microbiological analysis and phage host isolation. An additional $50 \mathrm{ml}$ of each cover brine sample was centrifuged at 13,000 $\times g$ (Eppendorf 5810R Centrifuge, Eppendorf North America, Inc., Westbury, 
NY, United States) and $4^{\circ} \mathrm{C}$ for $20 \mathrm{~min}$ to remove cells and solid particles. The $\mathrm{pH}$ of the supernatant was adjusted to approximately 6.3 with $5.0 \mathrm{~N} \mathrm{NaOH}$ using a Fisher Accumet $\mathrm{pH}$ meter (model AR25, Thermo Fisher Scientific, Pittsburgh, PA, United States) equipped with a Gel-Filled Pencil-Thin $\mathrm{pH}$ Combination Electrode. The $\mathrm{pH}$-adjusted supernatant was filtered brine through Nalgene filtration units with $0.45 \mu \mathrm{m}$ pore size and temporarily stored at $4^{\circ} \mathrm{C}$ until used for phage isolation.

\section{Bacterial Concentrations During the Fermentation}

Plate counts for presumptive Enterobacteriaceae and Lactobacillus were determined from Violet Bile Salt agar plates supplemented with $1 \%$ of glucose (VRBG) and de Man, Rogosa and Sharpe (MRS) agar plates supplemented with $1 \%$ of a $0.1 \%$ cycloheximide stock solution (Oxoid, Basingstoke, United Kingdom) as described by Pérez-Díaz et al. (2019). For comparison, the bacterial concentration on fresh cucumbers were also measured.

\section{Chemical Analyses}

Lactic acid concentration and $\mathrm{pH}$ were measured as described by Pérez-Díaz et al. (2019). Briefly, lactic acid concentration was measured by high-performance liquid chromatography analysis using a 30-cm HPX-87H column (Bio-Rad Laboratories, Hercules, CA, United States) as described by McFeeters and Barish (2003). The column was heated to $37^{\circ} \mathrm{C}$ and eluted with $0.03 \mathrm{~N}$ sulfuric acid at a flow rate of $1 \mathrm{ml} / \mathrm{min}$. A Thermo Separations UV6000 diode array detector (Spectra System Thermo Scientific, Waltham, MA, United States) was used to collect data at $210 \mathrm{~nm}$ for the analysis of lactic acid. External standards were used to calibrate the system. The $\mathrm{pH}$ of each cover brine sample was measured using a Fisher Accumet $\mathrm{pH}$ meter (model AR25, Fisher Scientific).

\section{Isolation of Gram-Negative Bacteria and Their Phages}

Colonies on VRBG agar plates were picked for purification, then stored and identified as described by Pérez-Díaz et al. (2019). Briefly, each purified bacterial isolate was then grown in Tryptic Soy Broth (TSB). Frozen stock of each isolate was prepared with TSB containing $15 \%$ glycerol as a cryoprotectant and maintained at $-80^{\circ} \mathrm{C}$. A total of 39 purified Gram-negative bacterial isolates were used as potential hosts for phage isolation.

For this study, fresh cultures were prepared in a 96-well microplate (Microplate I). Each well contained $200 \mu \mathrm{l}$ of TSB and was inoculated with one bacterial isolate. After overnight incubation at $37^{\circ} \mathrm{C}, 50 \mu \mathrm{l}$ of each culture in Microplate I was transferred into a new microplate (Microplate II) where each well contained $150 \mu \mathrm{l}$ of TSB and $50 \mu \mathrm{l}$ of the $\mathrm{pH}$-adjusted filtered cover brine (a potential phage source). After the incubation at $37^{\circ} \mathrm{C}$ for $24 \mathrm{~h}$, Microplate II was centrifuged ( $\mathrm{SH}-3000$ rotor, RC5B centrifuge, Sorvall, Newtown, CT, United States) at 4,000 rpm, $4^{\circ} \mathrm{C}$ for $20 \mathrm{~min}$. The supernatants from Microplate II were transferred into a new microplate (Microplate III). Spot tests were then performed by spotting $10 \mu \mathrm{l}$ of supernatant from a well in Microplate III onto the corresponding bacterial lawn resulted from $100 \mu \mathrm{l}$ overnight culture from the corresponding well in Microplate I. Primary phage-host relationships were indicated by positive spot-test plates after overnight incubation at $37^{\circ} \mathrm{C}$. The resulting phage isolates underwent two rounds of plaque purification according to the method described by Lu et al. (2003a). The glycerol stocks of phages were prepared and stored at $-80^{\circ} \mathrm{C}$ for later use.

\section{Identification of Phage Hosts}

Distinct phage hosts were determined based on phage typing. Each host was then identified by partial 16S rRNA gene sequencing and API 20E miniaturized biochemical testing as described by Pérez-Díaz et al. (2019). The 16S rRNA amplicons were in average $700 \mathrm{bp}$ in length. The substrate assimilations on the API20E strips were read after 24 and $48 \mathrm{~h}$, and the interpretation of the results was done after $48 \mathrm{~h}$. In the few cases were the $16 S$ rRNA sequencing analysis generated results different from the API20E analysis, a third identification tool was applied. The sequencing of the dnaJ housekeeping gene, applied as described by Pham et al. (2007), was utilized as a third identification tool. The dnaJ was sequenced for host no. 112, 113, 116,222 , and 231.

\section{Phage Characterization}

Eight phage isolates along with their corresponding hosts were selected and used in a cross-infection experiment (Table 2) with spot tests to determine their host ranges. Based on host ranges, distinct phages were identified. Those phages were further characterized based on their morphology, major structural protein profiles, and restriction endonuclease digestion patterns using the methods previously described by Lu et al. (2003a) with minor modifications. Briefly, phage lysates were centrifuged at $4,000 \times g$ for $20 \mathrm{~min}$ and filtered $(0.45 \mu \mathrm{m}$ pore size). The filtrates were treated with DNase I and RNase A. Phage particles were concentrated by polyethylene glycol precipitation and then purified by cesium chloride density gradient ultracentrifugation at $600,000 \mathrm{~g}$ for $6 \mathrm{~h}$ at $15^{\circ} \mathrm{C}$. The ultracentrifuge-purified phages were used for electron microscopy analysis, sodium dodecyl sulfate-polyacrylamide gel electrophoresis (SDS-PAGE), and DNA extraction. Phage samples were negatively stained with $2 \%(\mathrm{w} / \mathrm{v})$ aqueous uranyl acetate and examined by transmission electron microscopy at an accelerating voltage of $80 \mathrm{kV}$ in the Center for Electron Microscopy at North Carolina State University. SDS-PAGE was carried out with boiled phage samples loaded onto NuPAGE precast gradient minigels (4-12\% BisTris, Invitrogen Corporation, Carlsbad, CA, United States). Phage DNA was prepared from the concentrated lysate using the phenol-chloroform extraction method, and digested with several restriction endonucleases (EcoRI, EcoRV, HindIII, MspI, and SwaI) according to the supplier's recommendations (New England BioLabs, Woburn, MA, United States). The resulting DNA fragments were separated on the $1 \%$ agarose gel containing $0.001 \%$ SYBR Safe DNA gel stain (Invitrogen) by gel electrophoresis in tris-borate-EDTA buffer at 70V (constant voltage) for $2.5 \mathrm{~h}$. 
TABLE 1 | Phages and their corresponding hosts.

\begin{tabular}{|c|c|c|c|c|c|c|c|}
\hline \multirow{2}{*}{$\begin{array}{l}\text { Phage } \\
\text { ID }\end{array}$} & \multicolumn{7}{|c|}{ Host } \\
\hline & ID & $\begin{array}{l}\text { ID by } 16 S \text { rRNA } \\
\text { sequencing }\end{array}$ & Accession no. & $\begin{array}{l}\% \text { Identity/ } \\
\text { coverage }\end{array}$ & Identification by API 20E & $\%$ Identity & Comments \\
\hline$\Phi 102$ & 102 & Citrobacter freundii & $\mathrm{MH} 045681$ & $100 / 99$ & Citrobacter freundii & 84.2 & $\begin{array}{l}\text { Very good identification to } \\
\text { the genus }\end{array}$ \\
\hline$\Phi 103$ & 103 & Enterobacter cloacae & $\mathrm{MH045682}$ & $100 / 100$ & Enterobacter cloacae & 97.7 & Good identification \\
\hline$\Phi 107$ & 107 & Enterobacter sp. & $\mathrm{MH045685}$ & $99 / 100$ & Enterobacter cancerogenus & 99.3 & Very good identification \\
\hline$\Phi 109$ & 109 & Pantoea sp. & $\mathrm{MH} 045687$ & $100 / 99$ & Pantoea sp. & 91.1 & Good Identification \\
\hline$\Phi 111$ & 111 & Providencia rettgeri & MK514946 & $100 / 100$ & Providencia rettgeri & 99.9 & Good identification \\
\hline$\Phi 112$ & 112 & Enterobacter asburiae & MH045689 & $87 / 90$ & Serratia ficaria & 59.8 & Invalid identification \\
\hline$\Phi 113$ & 113 & Pseudocitrobacter anthropi & MK514947 & $100 / 100$ & $\begin{array}{l}\text { Pseudomonas } \\
\text { fluorescens/putida }\end{array}$ & 75 & $\begin{array}{l}\text { Good identification to the } \\
\text { genus }\end{array}$ \\
\hline$\Phi 115$ & 115 & $\begin{array}{l}\text { Enterobacter cloacae } \\
\text { subsp. cloacae }\end{array}$ & $\mathrm{MH045692}$ & $100 / 98$ & Enterobacter cloacae & 94 & Good identification \\
\hline$\Phi 116$ & 116 & Enterobacter sp. & MK514954 & $99.88 / 100$ & Leclercia adecarboxylata & 85.6 & Low discrimination \\
\hline$\Phi 117$ & 117 & Providencia rettgeri & MK514948 & $100 / 100$ & Providencia rettgeri & 99.2 & Very good identification \\
\hline$\Phi 119$ & 119 & $\begin{array}{l}\text { Enterobacter cloacae } \\
\text { subsp. cloacae }\end{array}$ & $\mathrm{MH045695}$ & $100 / 99$ & Enterobacter cloacae & 97.7 & Good identification \\
\hline$\Phi 220$ & 220 & Enterobacteriaceae & MH045696 & $100 / 97$ & Escherichia vulneris & 80.5 & Acceptable identification \\
\hline$\Phi 221$ & 221 & $\begin{array}{l}\text { Enterobacter cloacae } \\
\text { subsp. cloacae }\end{array}$ & MH045697 & $100 / 98$ & Enterobacter cloacae & 97.7 & Good identification \\
\hline$\Phi 222$ & 222 & Enterobacter sp. & $\mathrm{MH045698}$ & $94 / 100$ & Leclercia adecarboxylata & 85.6 & Low discrimination \\
\hline$\Phi 225$ & 225 & $\begin{array}{l}\text { Enterobacter cloacae } \\
\text { subsp. cloacae }\end{array}$ & MH045701 & $100 / 97$ & Enterobacter cloacae & 97.7 & Good identification \\
\hline$\Phi 226$ & 226 & Leclercia adecarboxylata & $\mathrm{MH045702}$ & $100 / 97$ & Leclercia adecarboxylata & 85.6 & Low discrimination \\
\hline$\Phi 227$ & 227 & Citrobacter freundii & $\mathrm{MH045703}$ & $100 / 98$ & Citrobacter freundii & 99.9 & Excellent identification \\
\hline$\Phi 228$ & 228 & $\begin{array}{l}\text { Enterobacter cloacae } \\
\text { subsp. cloacae }\end{array}$ & MK514949 & $100 / 100$ & Enterobacter cloacae & 97.7 & Good identification \\
\hline$\Phi 230$ & 230 & $\begin{array}{l}\text { Enterobacter cloacae } \\
\text { subsp. cloacae }\end{array}$ & MK514950 & $100 / 99$ & Enterobacter cloacae & 97.7 & Good identification \\
\hline$\Phi 231$ & 231 & Enterobacter sp. & $\mathrm{MH045705}$ & $98 / 99$ & Leclercia adecarboxylata & 85.6 & Low discrimination \\
\hline$\Phi 232$ & 232 & Citrobacter freundii & MK514951 & $89 / 99$ & Citrobacter freundii & 99 & Excellent identification \\
\hline$\Phi 233$ & 233 & Enterobacteriaceae & $\mathrm{MH045706}$ & $99 / 96$ & Escherichia vulneris & 99.1 & Very good identification \\
\hline$\Phi 235$ & 235 & Enterobacter sp. & $\mathrm{MH045708}$ & $100 / 98$ & Enterobacter cloacae & 97.7 & Good identification \\
\hline$\Phi 237$ & 237 & $\begin{array}{l}\text { Enterobacter cloacae } \\
\text { subsp. cloacae }\end{array}$ & $\mathrm{MH} 045710$ & $100 / 97$ & Enterobacter cloacae & 97.7 & Good identification \\
\hline$\Phi 238$ & 238 & Enterobacter sp. & $\mathrm{MH045711}$ & $100 / 97$ & Enterobacter cloacae & 97.7 & Good identification \\
\hline Ф239 & 239 & Leclercia adecarboxylata & $\mathrm{MH} 045712$ & $100 / 97$ & Leclercia adecarboxylata & 85.6 & Low discrimination \\
\hline
\end{tabular}

All isolates were obtained from a commercial cucumber fermentation in North Carolina, United States.

TABLE 2 | Host ranges of 8 enterobacterial phages.

\begin{tabular}{|c|c|c|c|c|c|c|c|c|c|}
\hline \multirow[t]{2}{*}{ ID } & \multirow[t]{2}{*}{ Host identification ${ }^{a}$} & \multicolumn{8}{|c|}{ Phage identification } \\
\hline & & $\Phi 107$ & $\Phi 115$ & $\Phi 220$ & $\Phi 225$ & $\Phi 226$ & $\Phi 231$ & $\Phi 238$ & $\Phi 239$ \\
\hline 107 & Enterobacter cancerogenus & + & + & & + & + & & + & \\
\hline 115 & Enterobacter cloacae subsp. cloacae & + & + & & + & & & & \\
\hline 220 & Enterobacteriaceae & & & + & & & & & \\
\hline 225 & Enterobacter cloacae subsp. cloacae & & & & + & & & & \\
\hline 226 & Leclercia adecarboxylata & & & & & + & & & \\
\hline 231 & Enterobacter sp. & + & & & & & + & & \\
\hline 238 & Enterobacter cloacae & & & & & & & + & \\
\hline 239 & Leclercia adecarboxylata & & & & & & & & + \\
\hline
\end{tabular}

a Host identification shown in this table is based on $16 S$ rRNA gene sequencing. 


\section{Phage Infection in Cucumber Juice}

Cucumber juice was used as a model system to evaluate the infectivity of a phage active against $E$. cancerogenus. The cucumber juice was prepared from fresh cucumbers (size 3A) as described by Zhai et al. (under review) and filtered $(0.45 \mu \mathrm{m}$ pore size). Phage $\Phi 107$ was added to a tube containing cucumber juice and host E. cancerogenus $107\left(10^{5} \mathrm{CFU} / \mathrm{ml}\right)$ at the initial multiplicity of infection (MOI) 1 or 100 . Cucumber juice containing only host (without phage) was used as a control. After briefly mixed, each tube was incubated in water bath at $37^{\circ} \mathrm{C}$. Hourly samples were taken from each tube and then properly diluted before plated onto tryptic soy agar plates. After incubated at $37^{\circ} \mathrm{C}$ overnight, each plate was examined to obtain plate counts used for calculation of cell concentration.

\section{Statistical Analysis}

One-way Analysis of variance (ANOVA) was performed using Statistica for Windows (StatSoft, Tulsa, OK, United States). Tukey's HSD test was used to compare the mean values of data for significant difference $(P<0.05)$.

\section{RESULTS}

\section{Bacterial Concentrations During the Fermentation}

The concentrations of Gram-negative bacteria and LAB on fresh cucumbers were 5.4 and $4.2 \mathrm{Log} \mathrm{CFU} / \mathrm{g}$, respectively (data not shown). Figure 1 shows the concentration profiles of bacteria during the fermentation over a 30-day period. Gram-negative bacterial concentration was 3.3 and $3.0 \mathrm{Log} \mathrm{CFU} / \mathrm{ml}$ on days 1 and 3 of the fermentation, respectively. Thereafter, the cell concentration rapidly decreased below detectable levels by day 7. In contrast, $\mathrm{LAB}$ concentration was $3.8 \mathrm{Log} \mathrm{CFU} / \mathrm{ml}$ on day 1, rapidly increased to $6.8 \mathrm{Log} \mathrm{CFU} / \mathrm{ml}$ on day 3 , reached the maximum (8.3 $\log \mathrm{CFU} / \mathrm{ml}$ ) on day 7 , and then gradually decreased to $5.5 \mathrm{Log} / \mathrm{ml}$ on day 30 . It was noticed that LAB concentration was slightly higher than Gram-negative bacterial concentration on day 1 . The overall bacterial profile is typical of a commercial cucumber fermentation (Pérez-Díaz et al., 2016).

\section{Chemical Analyses}

The fermentation started at $\mathrm{pH} 4.4$ in the recycled cover brine. Rapid lactic acid production was observed between day 3 and day 7 , which resulted in $\mathrm{pH}$ decrease to 3.5 (Figure 1). These changes were attributed to the rapid growth of $\mathrm{LAB}$ and resulting acid production during this period of time (Figure 1). After day 7, lactic acid concentration continued to increase (but not as rapidly as earlier) and $\mathrm{pH}$ decreased slightly. On day 30 , lactic acid concentration and the resulting $\mathrm{pH}$ reached $74 \mathrm{mM}$ and 3.4, respectively, which were typical of cucumber fermentations.

\section{Isolation of Gram-Negative Bacteria and Their Phages}

A total of 39 Gram-negative bacterial isolates were obtained from VRBG plates. Nineteen (nearly 50\%) of them were obtained from day 1 , and 20 from day 3 . No colonies were observed on VRBG plates on day 7 or thereafter, indicating that Gramnegative bacteria died off or their concentration was below the detection limit on day 7. This could be due to inhibitory effect of lactic acid produced, the resulting low $\mathrm{pH}$ (3.5), and possible other factors such as phage infection as discussed below. Using the $39 \mathrm{Gram}$-negative bacterial isolates as potential hosts and the cover brine samples as potential phage source, 26 phage isolates were obtained by spot tests (Table 1). The first 11 phages listed in Table 1 were obtained on day 1 , and the remaining 15 phages were obtained on day 3. Since no Gram-negative bacteria were isolated on day 7 and thereafter, no effort was made to isolate phages against Gram-negative bacteria on and after day 7.

\section{Host Identification}

Among the 39 Gram-negative bacterial isolates, 26 (or 67\%) of them were found to be sensitive to phage attack (Table 1). Based on the $16 S$ rRNA gene sequence analysis, 23 (or 88\%) of the hosts belong to the Enterobacteriaceae family, including 15 (or $65 \%)$ Enterobacter spp. Among the 23 hosts, 8 were identified as Enterobacter cloacae, 1 as Enterobacter asburiae, 6 as Enterobacter sp., 3 as Citrobacter freundii, 2 as Leclercia adecarboxylata, 1 as Pantoea sp., 1 as Escherichia vulneris, and one (ID 220) as another member in Enterobacteriaceae family identified as Escherichia vulneris by the API 20E system (Table 1).

The host identification using the API 20E system is in general agreement with that by the 16S rRNA gene sequencing (Table 1). That is, 23 host isolates belong to Enterobacteriaceae, one to Pseudomonas, and two to Providencia. Among the 26 hosts, 20 were identified to the species level, yielding excellent, very good, good, and acceptable species identifications in 2, 4, 13, and 1 case(s), respectively (Table 1 ). Five hosts (ID 116, 222, 226, 231, and 239) were identified as $L$. adecarboxylata with low discrimination (85.6\% identity). But two of them (ID 226 and 239) were also identified as L. adecarboxylata by the $16 \mathrm{~S}$ rRNA gene sequence analysis, and another three (ID 116, 222, and 231) as Enterobacter cloacae. Hosts 116, 222, and 231 were also identified as Enterobacter sp. by dnaJ sequencing with $89 \%$ query identity over $88-96 \%$ of the homolog sequences. The dnaJ sequences obtained for hosts 116, 222, and 231 can be located in GenBank using accession numbers MG678924, MG678933, and MG678927, respectively. It was noticed that the host (ID 112) with invalid identification (Serratia ficaria) was identified as E. asburiae by $16 S$ rRNA gene and the dnaJ sequence analyses. The accession number for the dnaJ sequence obtained from host 112 can be located with accession number MG678921 in GenBank.

\section{Phage Characterization}

Among the 26 phage isolates infecting Gram-negative bacteria, eight phages with unique host range were selected for characterization. The electron micrographs (Figure 2) show that all eight phages are tailed phages with icosahedral heads in the viral order Caudovirales. Two phages ( $\Phi 107$, and $\Phi 238)$ belong to the Myoviridae family, three phages ( $\Phi 231, \Phi 225$, and $\Phi 226)$ belong to the Siphoviridae family, and other three phages ( $\Phi 115$, $\Phi 239$, and $\Phi 220$ ) belong to the Podoviridae family. Table 2 

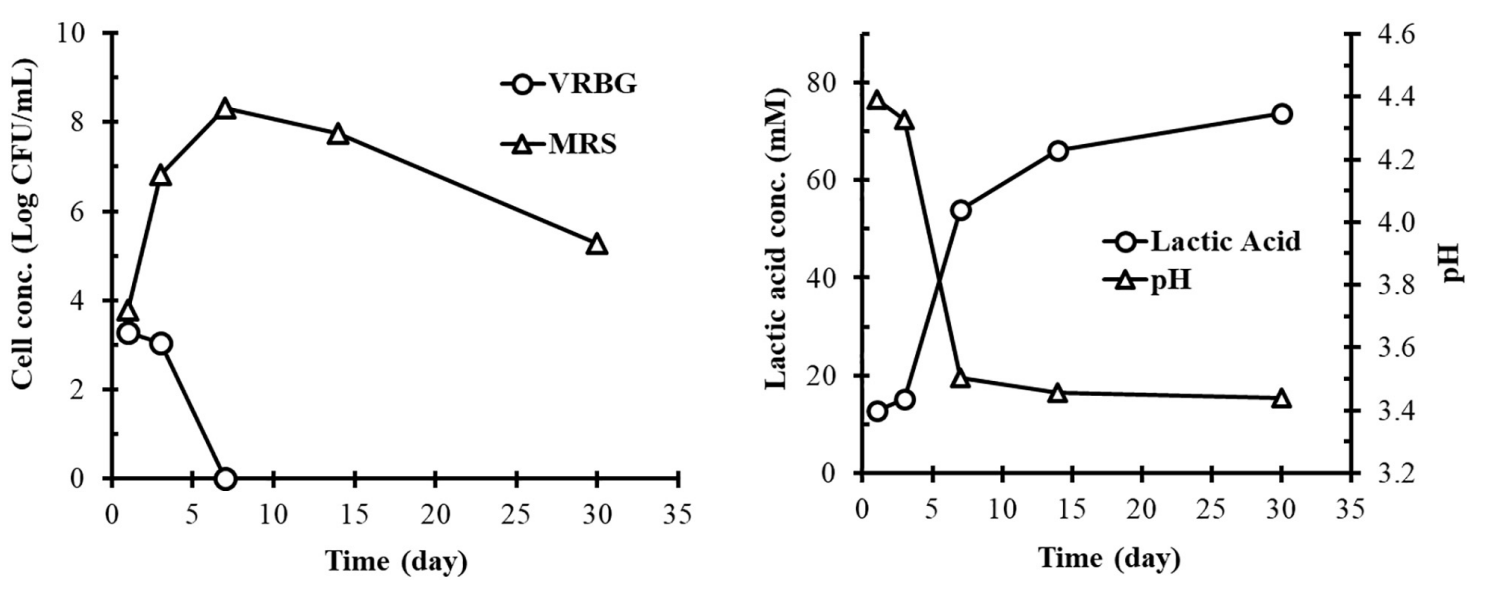

FIGURE 1 | Bacterial concentrations (left) and lactic acid production and pH (right) in the commercial cucumber fermentation studied. Plate counts from VRBG (o) and MRS $(\Delta)$ agar plates represent the concentrations of Gram-negative bacteria and lactic acid bacteria, respectively. Lactic acid production (o) and pH change $(\Delta)$ are shown in the right panel. Data points represent the mean and standard deviations of samples collected from the fermentation tank.

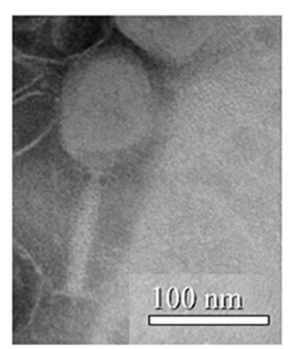

$\Phi 107$

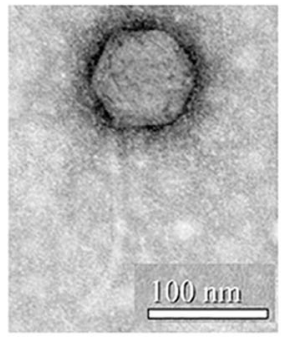

Ф226

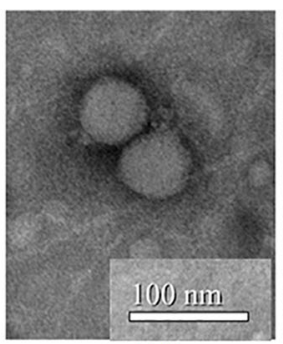

$\Phi 115$

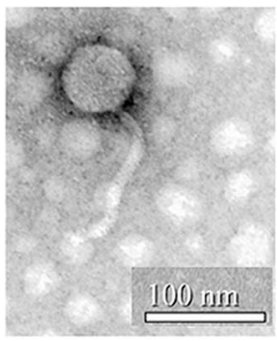

$\Phi 231$

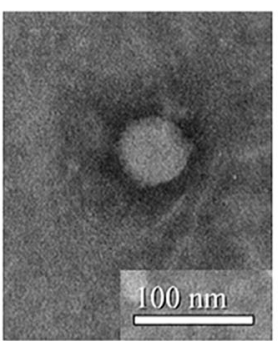

Ф 220

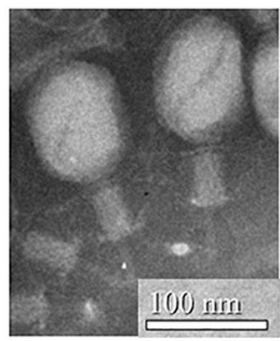

Ф238

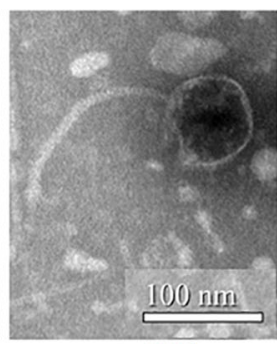

$\Phi 225$

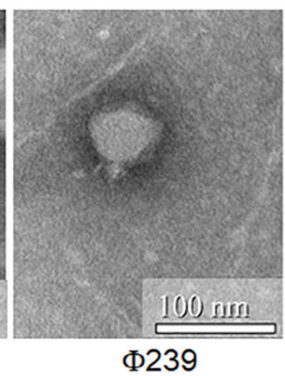

FIGURE 2 | Transmission electron micrographs of eight phages infecting Gram-negative bacteria in a commercial cucumber fermentation.

showed that the eight phages have different host ranges. The host identification was based on $16 S$ rRNA gene sequencing. Unfortunately, $16 S r R N A$ gene sequencing only identified the family name (Enterobacteriaceae) for host 220.

The SDS-PAGE analysis (Figure 3) showed that the structural protein profiles of the eight phages. Interestingly, the structural protein banding patterns of the two Myoviridae phages ( $\Phi 107$, and $\Phi 238$ ) are very similar (but not identical) to each other. The banding patterns of the three Siphoviridae phages ( $\Phi 225$, $\Phi 226$, and $\Phi 231$ ) are also similar to one another, but different from those of Myoviridae or Podoviridae phages which have fewer protein bands. The banding patterns of three Podoviridae phages ( $\Phi 115, \Phi 239$, and $\Phi 220)$ are only slightly different from one another, but very different from the other five phages. The analysis of restriction fragment length polymorphism (RFLP) was carried out using two restriction endonucleases, SwaI and $M s p$ I. The two Myoviridae phages ( 1107 , and $\Phi 238)$ showed the same restriction banding pattern from SwaI digestions (Figure 4A), but very different banding patterns from $M s p \mathrm{I}$ digestions (Figure 4B). The three Siphoviridae phages ( $\Phi 225$, Ф226, and $\Phi 231$ ) showed different restriction banding patterns from SwaI digestion (Figure 4A). Those banding patterns are not only different from one another, but also different from those of other phages. Digestion of the DNA from Podoviridae phage $\Phi 115$ with SwaI generated a fragment of 1900 bp (Figure 4A). The DNA from another Podoviridae phage $\Phi 239$ cannot be digested by SwaI (Figure 4A) but can be digested by MspI generating more than 10 restriction fragments (Figure 4B). In contrast, the DNA of Podoviridae phage $\Phi 220$ could neither be digested by SwaI (Figure 4A) nor by MspI (data not shown). 


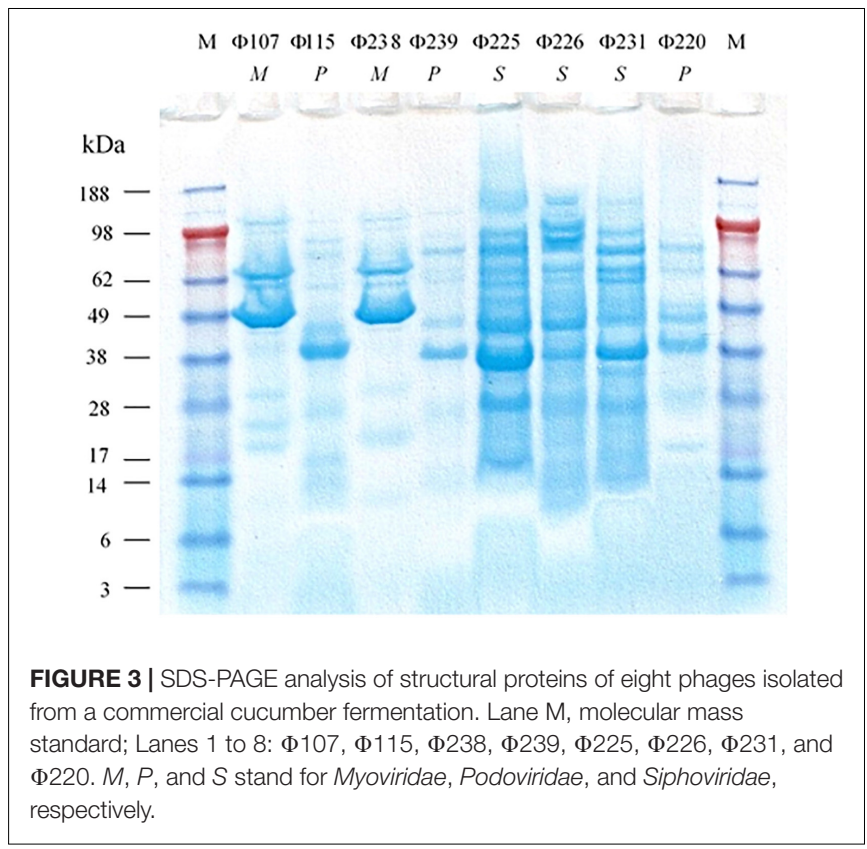

\section{Phage Infection in Cucumber Juice}

Cucumber juice contained most of the nutrients found in the whole cucumber and thus represents whole cucumbers. Because cucumber juice is a liquid and easy to work with, it was used as a model system to evaluate the infectivity of phage $\Phi 107$, which is active against its host E. cancerogenus 107. No salt, acid, and/or LAB were added to the model system to exclude their inhibitory effects against Gram-negative bacteria. During the first $2 \mathrm{~h}$, the host concentrations in the control tube (without phage) increased from $10^{5}$ to $1.4 \times 10^{6} \mathrm{CFU} / \mathrm{ml}$ (Figure 5). While the cell concentration in the infection tube at MOI 1 was similar to that of the control, the cell concentration in the infection tube at MOI 100 decreased rapidly and resulted in more than 4-log reduction (Figure 5). During the third hour, the cell concentration in the control tube continued to increase and reached $10^{7} \mathrm{CFU} / \mathrm{ml}$. In contrast, the cell concentrations in both infection tubes, regardless of the initial MOI, decreased to the undetectable level (below $10 \mathrm{CFU} / \mathrm{ml}$ ). That is, phage infection (regardless of the initial MOI) caused rapid cell death within $3 \mathrm{~h}$ and resulted in 5-log reductions in cell concentration compared to the initial cell concentration. Different from cells in the infection tubes, cells in the control tube continued to increase over next $2 \mathrm{~h}$ and reached $2.4 \times 10^{8} \mathrm{CFU} / \mathrm{ml}$.

\section{DISCUSSION}

The bacterial concentrations on fresh cucumbers and the fermentation profile obtained from the tank studied are in line with a typical industrial cucumber fermentation (PérezDíaz et al., 2015). The plate counts for presumptive LAB from MRS agar plates corresponding to the samples collected on day 1 of the fermentation are artificially higher due to the

\section{A}

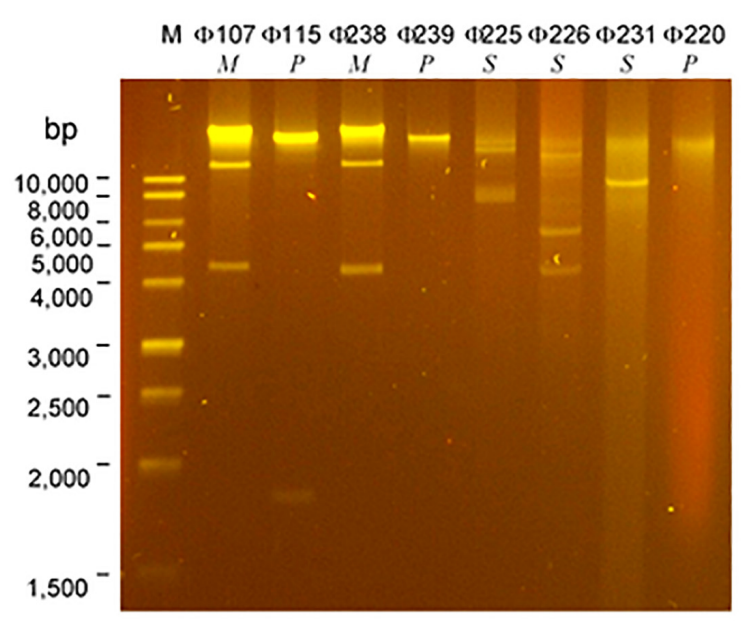

\section{B Mspl digestion}

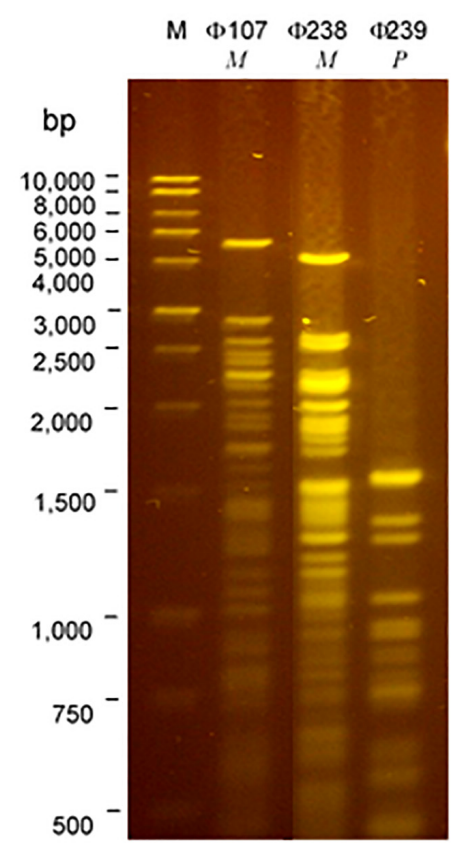

FIGURE 4 | Restriction analysis of DNAs of eight selected phages isolated from a commercial cucumber fermentation. Phage DNAs were digested with Swal (A) and Mspl (B). Lane M, 1-kb DNA ladder; Lanes 1-8: Ф107, Ф115, Ф238, Ф239, Ф225, Ф226, Ф231, and Ф220; Lanes 9-11: Lanes 1-8: Ф107, Ф238, and Ф239. 


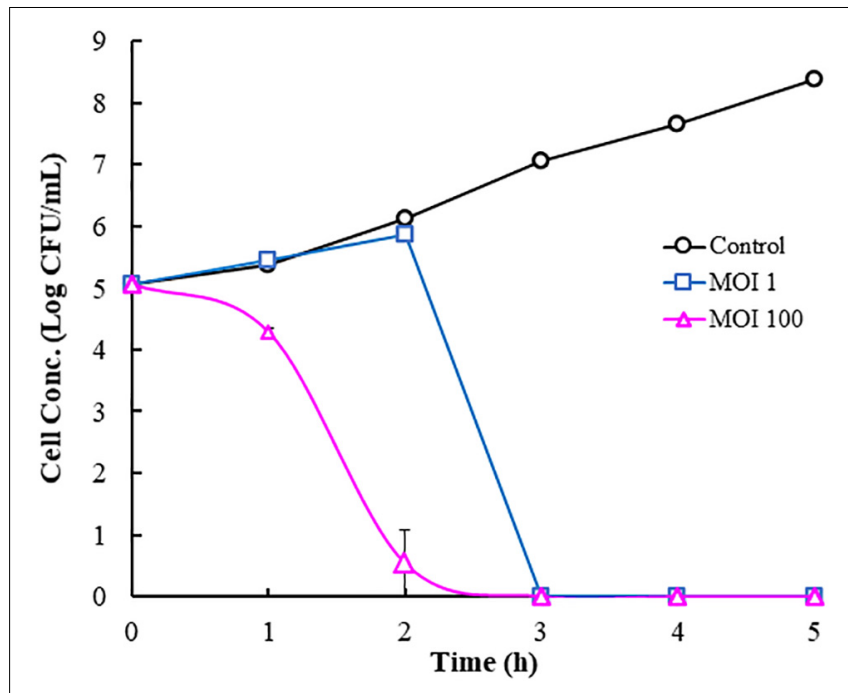

FIGURE 5 | Phage infection by $\Phi 107$ against Enterobacter cancerogenus 107 in cucumber juice.

fact that Exiguobacterium, Staphylococcus, Bacillus, Clostridium, and Aerococcus can also proliferate in such medium (PérezDíaz et al., 2019). The plate counts on VRBG and MRS plates from day 1 samples are likely impacted by the bacterial counts on the fresh cucumbers and inside the cucumbers due to the possible internalization from the skin to the endocarp during the equilibration between cucumbers and the cover brine. The observation that LAB concentration was higher than Gramnegative bacterial concentration on day 1 is because the recycled cover brine from previous cucumber fermentations already contained some LAB.

An abundance of phages against Enterobacteriaceae was found in the industrial fermentation cover brines, particularly those capable of infecting Enterobacter (Table 1). Phages were isolated from cover brines collected on days 1 and 3 , when the $\mathrm{pH}$ was above 4.3 , thus it is unknown if such phages can survive later in fermentations as the $\mathrm{pH}$ declines to 3.3 and their hosts died off. However, the prevalence of Enterobacteriaceae in the early stage of cucumber fermentations has been documented in the literature (Pederson and Albury, 1950; Mundt et al., 1967; Mundt and Hammer, 1968; Mundt, 1970; Pérez-Díaz et al., 2019). It is well known that Enterobacteriaceae produce gas when fermenting glucose and fructose (the major sugars in cucumbers), which can lead to cucumber bloater defect (Zhai et al., under review). The critical period for susceptibility of a fermentation to bloater defect is from day 1 to day 32 (Fleming et al., 1978).

In line with the prevalence of Enterobacteriaceae is the finding that at least $58 \%$ of phage hosts were Enterobacter species. A recent study on nine commercial cucumber fermentations showed that Enterobacter species were highly prevalent in the fermentations on days 1 and 3 (Pérez-Díaz et al., 2019). Among the Enterobacter isolates, 8 were identified as E. cloacae. Several studies reported that E. cloacae is the most frequently isolated Enterobacteriaceae from spoiled cucumber fermentations (Veldhuis and Etchells, 1939; Etchells, 1941; PérezDíaz et al., 2019). This Gram-negative facultative anaerobe is able to produce carbon dioxide and hydrogen in spoiled fermentations with an increased incidence of bloater defect (Etchells, 1941). E. cloacae is also able to convert lactic acid to propionic and butyric acids leading to an increase in $\mathrm{pH}$ (Samish et al., 1957, 1963; Franco et al., 2012; Breidt et al., 2013b; Franco and Pérez-Díaz, 2013; Pérez-Díaz et al., 2019).

Some isolated phage hosts can also induce spoilage or be a cause for a food safety concern. Pseudomonas species produce protease and lipase that can cause spoilage in meat, milk and dairy products (Walker, 1988). Citrobacter freundii, E. cloacae, E. vulneris, Pantoea agglomerans, and Providencia rettgeri are opportunistic human pathogens. Pseudomonas fragi and E. cancerogenus are true bacterial pathogens. It is speculated that if the Gram-negative bacteria described above survive in a cucumber fermentation and rapidly grow, the activity of LAB may be impaired. Further research is needed to test this hypothesis. If the presence of Gram-negative bacteria significantly impairs LAB activity, there will be more reasons to eliminate and/or control Gram-negative bacteria in the early stage of the fermentation.

Our observation that Gram-negative bacteria were excluded early in the fermentation is in agreement with those reported in the literature (Pérez-Díaz et al., 2019). The disappearance of Gram-negative bacteria in cucumber fermentation as well as other vegetable fermentations are often attributed only to chemical factors such as high salt concentration, the acids produced by $\mathrm{LAB}$, and the resulting low $\mathrm{pH}$ in the fermentation (Samish et al., 1963; Garrido-Fernández et al., 1997; Pérez-Díaz et al., 2019). However, other factors may also play a role in the bacterial mortality. Our data showed that $67 \%$ of the Gramnegative bacterial isolates were infected by diverse phages. Such high percentage of infected bacterial isolates is unexpected. We previously studied phages infecting LAB in the same cucumber fermentation and found that the percentage of LAB infected by phages was much lower (Lu et al., 2012). On day 1 and day 3, 0 and $13 \%$ of $\mathrm{LAB}$ isolates were attacked by phages, respectively. Even on day 14 (when the highest LAB phage activity was observed), only $28 \%$ of LAB isolates were attacked by phages ( $\mathrm{Lu}$ et al., 2012). Thus, the mortality of the Gram-negative bacteria caused by their phages cannot be overlooked. It is possible that phages played a significant role in the death of Gram-negative bacteria in the early stage of the fermentation, thereby facilitating the dominance of $\mathrm{LAB}$ and reducing bloater incidence.

The eight characterized phages showed distinct host ranges, indicating that they are different from each other. It is noticed that 4 phages $\Phi 107, \Phi 115, \Phi 225$, and $\Phi 238$ infected at least one E. cloacae strain. Specifically, $\Phi 225$ infected two E. cloacae strains while $\Phi 107, \Phi 115$, and $\Phi 238$ infected one of E. cloacae strains. In contrast, $\Phi 107, \Phi 115$, and $\Phi 238$ are capable of infecting two different species, E. cloacae and E. cancerogenus. Interestingly, Ф226 is capable of infecting bacteria in two different genera (Enterobacter and Leclercia). In the past, most phages were found species-specific and rarely crossing species boundaries (Beumer and Robinson, 2005). However, recent studies showed that some phages have a broad host range, crossing species or even genus 
barrier. We previously reported that many $\mathrm{LAB}$ phages isolated from vegetable fermentations are capable of infecting across Lactobacillus species, and two phages are capable of infecting Weissella cibaria, Lactobacillus plantarum, and Lactobacillus brevis (Lu et al., 2003b, 2012). Several other researchers showed that certain phages such as SFP10 and GG32 are capable of infecting both Salmonella enterica and E. coli O157:H7 (Park et al., 2012; Chae et al., 2016). Phages that are capable of crossing genera may use receptors, intermediary functions, or both, common to a wide range of bacteria (Bielke et al., 2007). Broad-host-range phages may play a key role in horizontal gene transfer between different species or genera of bacteria, thereby promoting genetic diversity in microbial communities (Jensen et al., 1998). Beumer and Robinson (2005) demonstrated that a broad-host-range, generalized transducing phage can acquire and carry $16 S$ rRNA gene sequences from bacteria belonging to different genera (Beumer and Robinson, 2005). While different phages can be differentiated by their host ranges, different bacterial species or strains can be distinguished by phage typing. Hosts 115, 225, and 238 are all identified as Enterrobacter cloacae or Enterobacter cloacae subsp. cloacae (Table 2). They differ in their susceptibilities to different sets of phages. Host 115 is sensitive to three different phages ( $\Phi 107, \Phi 115$, and $\Phi 225)$ while hosts 225 and 238 are sensitive to only one phage (Ф225 and $\Phi 238$, respectively). Therefore, these three hosts are different strains of E. cloacae. Hosts 226 and 239 are both identified as L. adecarboxylata, but they are sensitive to different phages, and thus they are different strains. Based on phage typing, the eight phage hosts are different from each other although they all belong to Enterobacteriaceae family. An interesting finding from SDS-PAGE analysis is that phages from the same family have similar structural protein profiles while phages from different families have very different structural protein profiles. We have not seen such interesting features when we studied LAB phages isolated from the same fermentation. There, LAB phages from the same family did not show similar structural protein profiles (Lu et al., 2012). Even though in this study phages from the same family share similar protein profiles, their protein profiles are not identical. Thus, the eight phages isolated in this study are different phages. Additionally, the RFLP results showed that the eight phages are genetically distinct, which provided a glimpse of the genetic diversity of phages against Gramnegative bacteria in cucumber fermentations. Further research will be needed to reveal the extent of the genetic diversity of phages from cucumber fermentations and to study the life cycles of these phages.

Because Enterobacter including E. cloacae and E. cancerogenus was highly prevalent in cucumber fermentations (Pérez-Díaz et al., 2019), Enterobacter is an important group of the gasproducing Gram-negative bacteria contributing to cucumber bloating (Veldhuis and Etchells, 1939; Etchells, 1941; Samish et al., 1957; Samish et al., 1963; Zhai et al., under review). In this study, 15 (or 58\%) of the isolated phages infected Enterobacter. It would be interesting to evaluate the effectiveness of one of those phages on the elimination of its host in cucumber juice as a model system. Host 107 (E. cancerogenus) was identified as one of the culprits in the causation of bloater defect in cucumber fermentations. It was able to produce high concentration of carbon dioxide in cucumber juice medium (Zhai et al., under review). In this study, $\Phi 107$ was selected to evaluate its effectiveness on the elimination of host 107 in cucumber juice used as a model system. The results showed that the infection of E. cancerogenus 107 by its phage $\Phi 107$ at the MOI of 1 or 100 effectively eliminated the host in cucumber juice within a short period of time in the absence of LAB and high salt concentration, the two factors thought to be critical in the die off of Gram-negative bacteria in cucumber fermentations. Our data clearly demonstrates that phage infection could potentially eliminate the target bacterial hosts effectively in cucumber fermentations. Since a diverse group of Gram-negative bacteria were found in the cucumber fermentation, a phage cocktail against those bacteria needs to be tested in the model system and applied in cucumber fermentations in order to completely prevent bloater formation. It is concluded that the abundant and varied phages active against Enterobacter and many other Gram-negative bacteria in cucumber fermentations can contribute to the eradication of those bacteria and induce changes in the microbial community, thereby promoting the dominance of LAB and also potentially minimizing bloater defect during cucumber fermentations. Therefore, the role of phages in the perishing of Gram-negative bacteria in cucumber fermentations cannot be overlooked and should be further investigated. It is likely that a combination of both chemical and biological factors including phages lead to the disappearance of Gram-negative bacteria and the dominance of $\mathrm{LAB}$ in cucumber fermentations.

\section{CONCLUSION}

The data from this study showed that abundant and diverse phages were present in a commercial cucumber fermentation, and $67 \%$ of Gram-negative bacterial isolates were sensitive to phage infection. These results suggest that phage infection could cause substantial mortality in the indigenous Gram-negative bacterial population in cucumber fermentations, and thus potentially influence the bacterial ecology, minimize bloater defect, and promote the quick dominance of LAB in cucumber fermentations. This study provides new insights into the functional role of phages in the dynamic process of cucumber fermentations. More studies are needed to further explore the phage ecology in other commercial cucumber fermentations in the same and different geographic locations, and to understand the factors shaping the microbial ecology of vegetable fermentations. To our knowledge, this is the first study to explore the ecology of phages infecting Gram-negative bacteria in commercial cucumber fermentations.

\section{DATA AVAILABILITY STATEMENT}

All datasets generated for this study are included in the article/supplementary material. 


\section{AUTHOR CONTRIBUTIONS}

ZL isolated and characterized phages and wrote the manuscript. IP-D and $\mathrm{JH}$ isolated and identified phage hosts. FB assisted with the electron microscopy analysis. IP-D and FB were involved in the manuscript revision. All authors contributed to the article and approved the submitted version.

\section{REFERENCES}

Anonymous, (2015). United States Department of Agriculture, 2015. Washington, DC: National Agricultural Statistics Service.

Anonymous, (2019). Pickles Market: Global Industry Trends, Share, Size, Growth, Opportunity and Forecast 2019-2024. Available at: https://www.imarcgroup.com/pickles-market (accessed December 22, 2019).

Beumer, A., and Robinson, J. B. (2005). A broad-host-range, generalized transducing phage (SN-T) acquires $16 \mathrm{~S}$ rRNA genes from different genera of bacteria. Appl. Environ. Microb. 71, 8301-8304. doi: 10.1128/aem.71.12.83018304.2005

Bielke, L., Higgins, S., Donoghue, A., Donoghue, D., and Hargis, B. M. (2007). Salmonella host range of bacteriophages that infect multiple genera. Poult. Sci. 86, 2536-2540. doi: 10.3382/ps.2007-00250

Breidt, F., and Caldwell, J. M. (2011). Survival of Escherichia coli O157:H7 in cucumber fermentation brines. J. Food Sci. 76, 198-203.

Breidt, F., McFeeters, R. F., Pérez-Díaz, I., and Lee, C. (2013a). "Fermented vegetables," in Food Microbiology: Fundamentals and Frontiers, 4th Edn, eds M. P. Doyle, and R. L. Buchanan, (Washington, DC: ASM Press), 841-855. doi: 10.1128/9781555818463.ch33

Breidt, F., Medina, E., Wafa, D., Pérez-Díaz, I., Franco, W., Huang, H. Y., et al. (2013b). Characterization of cucumber fermentation spoilage bacteria by enrichment culture and $16 \mathrm{~S}$ rDNA cloning. J. Food Sci. 78, 470-476. doi: 10.1111/1750-3841.12057

Chae, S.-J., Kwon, T., Lee, S., Kang, Y. H., Chung, G. T., Kim, D.-W., et al. (2016) Genome sequence of bacteriophage GG32, which can infect both Salmonella enterica serovar Typhimurium and Escherichia coli O157:H7. Genome Announc. 4, e802-e816. doi: 10.1128/genomeA.00802-16

Etchells, J. L. (1941). A New Type of Gaseous Fermentation Occurring During the Salting of Cucumbers, Vol. III. Ann Arbor, MI: Univ Microfilms Abstr, 7-8.

Fleming, H. P. (1979). Purging carbon dioxide from cucumber brines to prevent bloater damage-a review. Pickle Pak Sci. 6, 8-22.

Fleming, H. P., Thompson, R. L., and Monroe, R. J. (1978). Susceptibility of pickling cucumbers to bloater damage by carbonation. J. Food Sci. 43, 892-896 doi: 10.1111/j.1365-2621.1978.tb02449.x

Franco, W., and Pérez-Díaz, I. M. (2013). Microbial interactions associated with secondary cucumber fermentation. J. Appl. Microbiol. 114, 161-172. doi: 10. $1111 /$ jam. 12022

Franco, W., Pérez-Díaz, I. M., Johanningsmeier, S. D., and McFeeters, R. F. (2012). Characteristics of spoilage-associated secondary cucumber fermentation. Appl. Environ. Microbiol. 78, 1273-1284. doi: 10.1128/aem.066 05-11

Garrido-Fernández, A., Fernández-Díez, M. J., and Adams, R. M. (1997). Table Olives: Production and Processing. London: Chapman \& Hall.

Jensen, E. C., Schrader, H. S., Rieland, B., Thompson, T. L., Lee, K. W., Nickerson, K. W., et al. (1998). Prevalence of broad-host-range lytic bacteriophages of Sphaerotilus natans, Escherichia coli, and Pseudomonas aeruginosa. Appl. Environ. Microbiol. 64, 575-580. doi: 10.1128/aem.64.2.575-580. 1998

Kaplan, J. K. (2014). A lab that keeps us all out of a pickle. Agric. Res. 7, 1-9.

Lu, Z., and Breidt, F. (2015). Escherichia coli O157:H7 bacteriophage (241 isolated from an industrial cucumber fermentation at high acidity and salinity. Front. Microbiol. 6:67. doi: 10.3389/fmicb.2015. 00067

\section{ACKNOWLEDGMENTS}

We thank Mount Olive Pickle Company in Raleigh, NC for help with sample collection from the commercial cucumber fermentation tank for this study. We also thank Ms. Sandra Parker for excellent secretarial assistance.

Lu, Z., Breidt, F., Fleming, H. P., Altermann, E., and Klaenhammer, T. R. (2003a). Isolation and characterization of a Lactobacillus plantarum bacteriophage (JL1 from a cucumber fermentation. Int. J. Food Microbiol. 84, 225-235. doi: 10.1016/s0168-1605(03)00111-9

Lu, Z., Breidt, F., Plengvidhya, V., and Fleming, H. P. (2003b). Bacteriophage ecology in commercial sauerkraut fermentations. Appl. Environ. Microbiol. 69, 3192-3202. doi: 10.1128/aem.69.6.3192-3202.2003

Lu, Z., Pérez-Díaz, I. M., Hayes, J. S., and Breidt, F. (2012). Bacteriophage ecology in an industrial cucumber fermentation. Appl. Environ. Microbiol. 78, 8571-8578. doi: 10.1128/aem.01914-12

McFeeters, R. F., and Barish, A. O. (2003). Sulfite analysis of fruits and vegetables by high-performance liquid chromatography (HPLC) with ultraviolet spectrophotometric detection. J Agric. Food Chem. 51, 1513-1517. doi: $10.1021 /$ jf025693c

Mundt, J. O. (1970). Lactic acid bacteria associated with raw plant food material. J. Milk Food Technol. 33, 550-553. doi: 10.4315/0022-2747-33.12.550

Mundt, J. O., Graham, W. F., and McCarty, I. E. (1967). Spherical lactic acidproducing bacteria of southern-grown raw and processed vegetables. Appl. Microbiol. 15, 1303-1308. doi: 10.1128/aem.15.6.1303-1308.1967

Mundt, J. O., and Hammer, J. L. (1968). Lactobacilli on plants. Appl. Microbiol. 16, 1326-1330. doi: 10.1128/aem.16.9.1326-1330.1968

Park, M., Lee, J.-H., Shin, H., Kim, M., Choi, J., Kang, D.-H., et al. (2012) Characterization and comparative genomic analysis of a novel bacteriophage, SFP10, simultaneously inhibiting both Salmonella enterica and Escherichia coli O157: H7. Appl. Environ. Microbiol. 78, 58-69. doi: 10.1128/aem.06231-11

Pederson, C. S., and Albury, M. N. (1950). Effect of Temperature Upon Bacteriological and Chemical Changes in Fermenting Cucumbers. Geneva: New York State Agricultural Experiment Station.

Pérez-Díaz, I. M., Breidt, F., Buescher, R. W., Arroyo-Lopez, F. N., Jimenez-Diaz R., Bautista-Gallego, J., et al. (2014). "Fermented and acidified vegetables," in Compendium of Methods for the Microbiological Examination of Foods, fifth Edn, eds P. Downes, and K. Ito, (Washington, DC: American Public Health Association).

Pérez-Díaz, I. M., Breidt, F., Buescher, R. W., Arroyo-López, F. N., Jiménez-Díaz, R., Garrido-Fernandez, A., et al. (2015). "Fermented and acidified vegetables," in Compendium of Methods for the Microbiological Examination of Foods, fourth Edn, eds P. Downes, and K. Ito, (Washington, DC: American Public Health Association), 521-532.

Pérez-Díaz, I. M., Hayes, J., Medina, E., Webber, A. M., Butz, N., Dickey, A. N., et al. (2019). Assessment of the Non-lactic acid bacteria microbiota in fresh cucumbers and commercially fermented cucumber pickles brined with $6 \%$ NaCl. Food Microbiol. 77, 10-20. doi: 10.1016/j.fm.2018.08.003

Pérez-Díaz, I. M., Hayes, J. S., Medina-Pradas, E., Anekella, K., Daughtry, K. V., Dieck, S., et al. (2016). Reassessment of the succession of lactic acid bacteria in commercial cucumber fermentations and physiological and genomic features associated with their dominance. Food Microbiol. 63, 217-227. doi: 10.1016/j. fm.2016.11.025

Pham, H. N., Ohkusu, K., Mishima, N., Noda, M., Monir Shah, M., Sun, X., et al. (2007). Phylogeny and species identification of the family Enterobacteriaceae based on dnaJ sequences. Diagn. Microbiol. Infect. Dis. 58, 153-161. doi: 10. 1016/j.diagmicrobio.2006.12.019

Samish, Z., Etinger-Tulczynska, R., and Bick, M. (1957). The presence of bacteria within cucumber tissue. Rec. Agric. Res. Station 8:101.

Samish, Z., Etinger-Tulczynska, R., and Bick, M. (1963). The microflora within the tissue of fruits and vegetables. J. Food Sci. 28, 259-266. doi: 10.1111/j.13652621.1963.tb00194.x 
Veldhuis, M. K., and Etchells, J. L. (1939). Gaseous products of cucumber pickle fermentations. Food Res. 4, 621-630. doi: 10.1111/j.1365-2621.1939.tb17 159.x

Walker, S. J. (1988). Major spoilage microorganisms in milk and dairy products. J. Soc. Dairy Tech. 41, 91-92. doi: 10.1111/j.1471-0307.1988.tb00 606.X

Zhai, Y., Pérez-Díaz, I. M., and Diaz, J. T. (2018). Viability of commercial cucumber fermentation without nitrogen or air purging. Trends Food Sci. Tech. 81, 185-192. doi: 10.1016/j.tifs.2018.05. 017
Conflict of Interest: The authors declare that the research was conducted in the absence of any commercial or financial relationships that could be construed as a potential conflict of interest.

Copyright (c) 2020 Lu, Pérez-Díaz, Hayes and Breidt. This is an open-access article distributed under the terms of the Creative Commons Attribution License (CC BY). The use, distribution or reproduction in other forums is permitted, provided the original author(s) and the copyright owner(s) are credited and that the original publication in this journal is cited, in accordance with accepted academic practice. No use, distribution or reproduction is permitted which does not comply with these terms. 